\title{
Caracterização físico-química e aminas bioativas em vinhos da cv. Syrah I - Efeito do ciclo de produção
}

\author{
Physico-chemical characterization and bioactive amines in \\ Syrah wines I - Influence of growing season
}

\author{
Renata Vieira da MOTA ${ }^{1 *}$, Daniel Angelucci de AMORIM ${ }^{1}$, Ana Carolina FÁVERO², \\ Maria Beatriz Abreu GLORIA ${ }^{3}$, Murillo de Albuquerque REGINA ${ }^{1}$
}

\section{Resumo}

A ocorrência sistemática de dias chuvosos ou com alta nebulosidade e temperaturas ambientais elevadas prejudicam a maturação e a sanidade das uvas. Estudos recentes indicam que a alteração do ciclo de produção da videira através da poda possibilita colher uvas em épocas mais favoráveis à maturação, e com níveis de produção aceitáveis. Neste sentido, o presente trabalho teve como objetivo avaliar o perfil analítico dos vinhos de Syrah de safras de verão e inverno dos anos 2005 e 2006 produzidos em Três Corações (MG). Os vinhos do inverno de 2005 apresentaram valores superiores de $\mathrm{pH}(3,91 \times 3,59)$, polifenóis totais $(49,2 \times 32,5)$, intensidade de cor $(10,75 \times 5,68)$, antocianinas $\left(121,48 \times 41,09 \mathrm{mg} . \mathrm{L}^{-1}\right)$, fenólicos totais $\left(2,06 \times 1,21\right.$ g.L $\left.\mathrm{L}^{-1}\right)$, álcool $(12,65 \times 10,78 \% \mathrm{v} / \mathrm{v})$ e aminas bioativas $\left(10,36 \times 4,46 \mathrm{mg} . \mathrm{L}^{-1}\right)$ quando comparados aos de verão. Comportamento semelhante foi obtido na safra de 2006. Os vinhos de inverno apresentaram maior conteúdo de compostos fenólicos, o que indica maior qualidade e maior potencial de guarda. Entretanto, o cultivo em estação seca e o elevado pH do mosto contribuíram para um aumento no teor de aminas bioativas, cuja evolução deve ser controlada na vinificação para evitar riscos à saúde humana.

Palavras-chave: Vitis vinifera; produção extemporânea; maturação; composição; aminas bioativas.

\begin{abstract}
The systematic incidence of rainfall or overcast conditions and high temperatures impair grapes maturation and sanity. Recent studies show that vine growing season alteration through pruning enables berries harvest in climatic conditions more favorable to fruit maturation and that vines respond to pruning with acceptable yield levels. Under these conditions, the objective of the present work was to evaluate the physico-chemical characteristics of Syrah wine from winter and summer vintages of 2005 and 2006 cultivated in the city of Três Corações, State of Minas Gerais, Brazil. The winter wine from the 2005 vegetative cycle showed higher values of $\mathrm{pH}(3.91 \times 3.59)$, total polyphenols $(49.2 \times 32.5)$, color intensity $(10.75 \times 5.68)$, anthocyanins $\left(121.48 \times 41.09 \mathrm{mg} . \mathrm{L}^{-1}\right)$, total phenols $\left(2.06 \times 1.21 \mathrm{~g} . \mathrm{L}^{-1}\right)$, alcohol $(12.65 \times 10.78 \% \mathrm{v} / \mathrm{v})$, and bioactive amines $\left(10.36 \times 4.46 \mathrm{mg} . \mathrm{L}^{-1}\right)$ when compared to the summer wine. Similar results were observed for winter and summer wines from the 2006 vintage. Winter wines showed higher levels of phenolic compounds, which means better quality and aging potential. However, grapes cultivation under dry weather conditions and high $\mathrm{pH}$ contributed to increase bioactive amines levels. Such evolution should be followed during vinification to avoid toxicological risk.
\end{abstract}

Keywords: Vitis vinifera; extemporaneous production; ripening; composition; bioactive amines.

\section{Introdução}

$\mathrm{Na}$ maioria das regiões vitícolas brasileiras o período de colheita das uvas coincide com a época de maior intensidade pluviométrica, condição que afeta negativamente a qualidade dos vinhos obtidos, em especial a dos vinhos tintos. A ocorrência sistemática de dias chuvosos ou com alta nebulosidade, aliada às temperaturas ambientais elevadas prejudica não só a maturação das uvas, mas também a sua sanidade devido à ocorrência de inúmeras podridões dos cachos. Nessas condições, os viticultores são levados a antecipar o período da vindima, o que afeta negativamente a qualidade futura do vinho (JACKSON; LOMBARD, 1993).
A obtenção de um vinho de qualidade depende da composição das bagas no momento da colheita (teores de açúcares, ácidos, taninos, antocianinas, polifenóis não oxidáveis, aromas, enzimas oxidorredutoras e microelementos). Esta garante o caráter distintivo e de qualidade e está diretamente relacionado com o ecossistema vitícola (clima, solo, cultivar, porta-enxerto) e com as técnicas culturais (irrigação, controle de pragas e doenças, adubação). Dos fatores relacionados ao ecossistema, o clima aparece como o componente de maior influência na qualidade do mosto, seguido pela disponibilidade hídrica e pelo tipo de solo (Van LEEUWEN et al., 2004; UBALDE et al., 2007).

\footnotetext{
Recebido para publicação em 5/10/2007

Aceito para publicação em 7/4/2008 (002905)

${ }^{1}$ Núcleo Tecnológico Empresa de Pesquisa Agropecuária de Minas Gerais - EPAMIG Uva e Vinho, Av. Santa Cruz, 500, CEP 37780-000, Caldas - MG, Brasil,

E-mails: renata@epamigcaldas.gov.br; daniel@epamigcaldas.gov.br; murillo@epamigcaldas.gov.br

2 Universidade Federal de Lavras - UFLA, CP 3037, CEP 37200-000, Lavras - MG, Brasil, E-mail: acfavero@yahoo.com.br

${ }^{3}$ Laboratório de Bioquímica de Alimentos, Faculdade de Farmácia, Universidade Federal de Minas Gerais - UFMG, Av. Antonio Carlos, 6627, CEP 31270-901, Belo Horizonte - MG, Brasil, E-mail: mbeatriz@ufmg.br

${ }^{*}$ A quem a correspondência deve ser enviada
} 
Estudos recentes realizados na região Sudeste têm mostrado que a alteração do ciclo de produção da videira por meio da poda constitui uma das principais formas de se conseguir colher uvas em épocas mais favoráveis à maturação, e que a videira responde a esta prática com níveis de produção aceitáveis (AMORIM; FAVERO; REGINA, 2005; FAVERO, 2007). Tal manejo é possível em regiões onde as temperaturas ambientais permitem a obtenção de mais de um ciclo anual, condição que ocorre em várias regiões mineiras, tais como o cerrado e a região cafeeira situada no sul do Estado (TONIETTO; VIANELLO; REGINA, 2006; REGINA et al., 2006; FAVERO, 2007). A característica climática mais desejável para a melhoria da qualidade dos vinhos destas regiões é a ocorrência de um período seco com alternância de temperatura entre noite e dia. Este fator é indispensável à obtenção de vinhos tintos de qualidade pela influência positiva exercida na maturação da uva, mais especificamente na síntese e no acúmulo dos polifenóis (GUERRA, 2002).

As aminas bioativas em uvas e vinhos são importantes tanto do ponto de vista tecnológico quanto toxicológico. As poliaminas são essenciais para a produtividade e qualidade das uvas. Entretanto, as aminas biogênicas, quando em elevadas concentrações, podem causar risco à saúde de indivíduos sensíveis, além de apresentarem efeito negativo no sabor e aroma do vinho. Além disso, podem ser utilizadas para indicar as condições edafoclimáticas prevalentes durante a produção e as higiênico-sanitárias durante o processamento (SOUZA et al., 2005; GLÓRIA; VIEIRA, 2007).

O presente trabalho teve como objetivo avaliar o perfil analítico, incluindo as características físico-químicas e as aminas bioativas dos vinhos de Syrah elaborados a partir de uvas colhidas no verão e no inverno na região de Três Corações, sul do Estado de Minas Gerais, nas safras de 2005 e 2006.

\section{Material e métodos}

\subsection{Produção da uva}

O trabalho foi conduzido em vinhedos de Syrah clone 747 instalados em Três Corações, no sul do Estado de Minas Gerais, Brasil, durante as safras de 2005 e 2006. Três Corações está classificado como clima Cwa - temperado quente (mesotérmico), situado à latitude de $21^{\circ} 41^{\prime} \mathrm{S}$, longitude de $45^{\circ} 15^{\prime} \mathrm{W}$, altitude de $865 \mathrm{~m}$. Possui insolação anual de $2334 \mathrm{~h}$, umidade relativa do ar média de $72,3 \%$, temperatura máxima média do ar de $26,7^{\circ} \mathrm{C}$, e amplitude térmica diária média de $12,6^{\circ} \mathrm{C}$ (TONIETTO; VIANELLO; REGINA, 2006). A Figura 1 e a Tabela 1 ilustram as características climáticas observadas durante o período do experimento.

As videiras, enxertadas sobre o porta-enxerto $3309 \mathrm{C}$, foram conduzidas em espaldeira com espaçamento de 2,70 × 1,20 m, com densidade de 3084 plantas por hectare. As plantas foram formadas em duplo cordão esporonado e podadas com poda curta e com uma carga média de 60.000 gemas por hectare. Durante as safras avaliadas o vinhedo encontrava-se com 4 e 5 anos de idade, sendo submetido a duas podas anuais, conforme o ciclo de produção desejado. Para o ciclo de verão (colheita em janeiro), as plantas foram podadas em agosto e, para o ciclo de inverno (colheita em julho), a poda foi realizada em janeiro. Desta forma, as plantas só permaneceram em repouso vegetativo entre o final do ciclo de inverno e o início do ciclo de verão, ou seja, entre o final de julho e o início de agosto.

Os cachos foram colhidos no ponto de maturação tecnológico determinado pelo acompanhamento semanal dos teores de sólidos solúveis totais (refratômetro manual ATAGO), pH e acidez titulável no mosto, obtido por prensagem manual de 210 bagas.

Em cada safra foram considerados dois tratamentos (verão e inverno) e três repetições do mosto, cada uma obtida a partir da prensagem manual de 70 bagas. A comparação das médias em cada safra foi feita pelo teste de Tukey a $5 \%$ de probabilidade.

\subsection{Elaboração do vinho}

A vinificação foi realizada na vinícola experimental do Núcleo Tecnológico EPAMIG Uva e Vinho, em Caldas (MG). Em cada
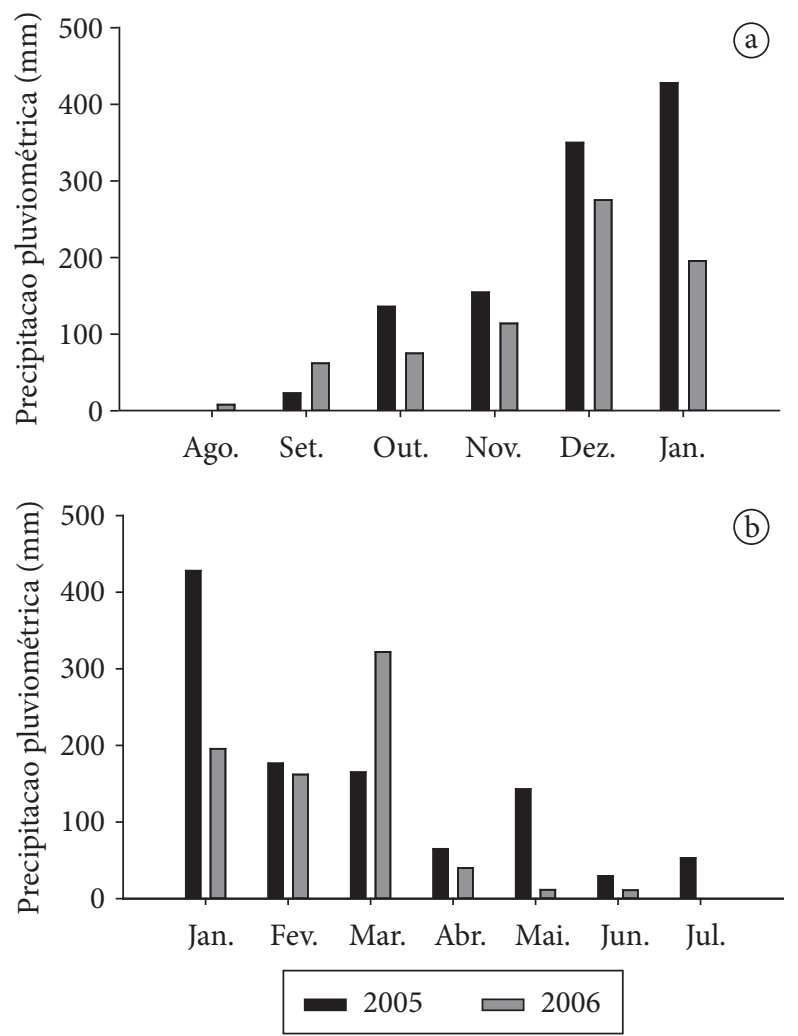

Figura 1. Precipitação pluviométrica total mensal durante as safras de verão 2005 e 2006 (a) e inverno 2005 e 2006 (b), no município de Três Corações (MG).

Tabela 1. Temperatura média máxima e mínima e amplitude térmica média na região dos cachos, durante o período de maturação de frutos da videira Syrah em ciclo de verão e inverno no município de Três Corações (MG). Safras de 2005 e 2006.

\begin{tabular}{lrrrrrr}
\hline \multirow{2}{*}{ Temperatura média $\left({ }^{\circ} \mathrm{C}\right)$} & \multicolumn{2}{c}{ Safra 2005} & & \multicolumn{2}{c}{ Safra 2006} \\
\cline { 2 - 3 } \cline { 6 - 7 } & Verão & Inverno & & Verão & Inverno \\
\hline Máxima & 29,1 & 24,3 & & 28,1 & 25,1 \\
Mínima & 16,7 & 9,5 & & 15,5 & 7,8 \\
Amplitude térmica (máx.-mín.) & 12,4 & 14,8 & & 12,6 & 17,3 \\
\hline
\end{tabular}


safra foram colhidos $200 \mathrm{~kg}$ de uvas em caixas de colheita com capacidade de $15 \mathrm{~kg}$, transportadas até a vinícola onde se realizou a limpeza dos cachos, eliminando-se bagas atacadas por pássaros e/ou marimbondos e cachos impróprios para vinificação. As uvas foram armazenadas em câmara fria, a $5^{\circ} \mathrm{C}$, por 14 horas. Em seguida, foram desengaçadas e as bagas levemente prensadas, utilizando-se uma desengaçadeira-esmagadeira de aço inox. Neste momento adicionou-se $\mathrm{SO}_{2}$ gasoso a $50 \mathrm{mg}$. $\mathrm{L}^{-1}$ ao mosto que foi separado em dois lotes correspondentes a $100 \mathrm{~kg}$ cada. Os lotes foram acondicionados em dois tanques fermentadores de aço inox com capacidade de $110 \mathrm{~L}$ e adicionaram-se leveduras secas ativas (Saccharomyces cereviseae) AWRI 796 na concentração de 0,20 g. $\mathrm{L}^{-1}$. Os tanques permaneceram em ambiente com temperatura controlada a $24^{\circ} \mathrm{C}$. A correção com açúcar (chaptalização) foi realizada, quando necessário, para obtenção de vinhos com 11 e 12\% v/v de álcool (RIBÉREAUGAYON et al., 2004). Durante o período de maceração realizaram-se duas remontagens por dia. Após 10 dias realizou-se a descuba, transferindo-se o vinho gota para recipientes de vidro com capacidade de $13 \mathrm{~L}\left(\right.$ Pyrex $\left.^{\circ}\right)$, dotados de válvula tipo Muller, finalizando a fermentação alcoólica. Ao final da fermentação malolática, acompanhada pela determinação do ácido málico por cromatografia em papel, os vinhos foram trasfegados e corrigidos os valores de $\mathrm{SO}_{2}$ livre para $30 \mathrm{mg} \cdot \mathrm{L}^{-1}$. Em seguida, foram colocados em câmara fria a $-3{ }^{\circ} \mathrm{C}$ para estabilização tartárica por quinze dias. Após duas trasfegas adicionais, em intervalos de três meses, os vinhos foram engarrafados em garrafas de $750 \mathrm{~mL}$ e acondicionados na cave.

\subsection{Análise físico-química dos vinhos}

Os vinhos foram analisados quanto a composição físico-química após 13 e 2 meses de armazenamento para as safras de 2005 e 2006, respectivamente. Devido a diferença no período de armazenamento, não foram realizadas comparações de composição entre as safras, apenas entre os tratamentos (verão e inverno) em cada safra avaliada. Além disso, como não foi feita repetição de vinificação dos tratamentos, não foi realizada análise estatística comparativa das médias obtidas para a composição dos vinhos.

A densidade do vinho foi obtida em densímetro digital (Gehaka modelo DSL-950); o pH em potenciômetro digital (Micronal modelo B 474), equipado com eletrodo de vidro e calibrado com soluções padrão de pH 4,0 e 7,0; o grau alcoólico, determinado no destilado do vinho obtido em destilador Super DEE Gibertini, foi obtido da tabela 913.02 da AOAC (1995) correspondente à densidade do destilado do vinho a $20^{\circ} \mathrm{C}$; os teores de dióxido de enxofre livre e total foram obtidos pelo método Ripper segundo AMERINE e OUGH (1980); a acidez pela titulação do vinho com $\mathrm{NaOH} 0,1 \mathrm{~N}$, utilizando-se fenolftaleína como indicador; e a acidez volátil pelo arraste do vapor obtido em destilador Super DEE Gibertini e titulação com $\mathrm{NaOH}$ 0,1 N, utilizando-se fenolftaleína como indicador.

Os açúcares redutores foram determinados pelo método colorimétrico de Somogy-Nelson a $510 \mathrm{~nm}$ com base em uma curva analítica de glicose; o extrato seco por evaporação em estufa a $105^{\circ} \mathrm{C}$ por 3 horas segundo método 920.62 da AOAC (1995); as cinzas pela incineração de $5 \mathrm{~mL}$ de vinho em cadinhos de porcelana a $550{ }^{\circ} \mathrm{C}$ (AMERINE; OUGH, 1980); e o potássio em fotômetro de chama Micronal modelo B262 calibrado com soluções padrão K de 30 a 150 mg. $\mathrm{L}^{-1}$ s segundo método 965.30 da AOAC (1995).

O teor de antocianinas foi obtido pelo método do $\mathrm{pH}$ diferencial (GIUSTI; WROLSTAD, 2000) e o resultado expresso em mg de malvidina-3-glicosídeo por litro de vinho, considerando-se o peso molecular de 529 g. $\mathrm{mol}^{-1}$ e coeficiente de absortividade molar de $28.000 \mathrm{mol.L}^{-1}$; os fenólicos totais pelo método de Folin-Ciocalteau com base em uma curva analítica de ácido gálico (AMERINE; OUGH, 1980); os polifenóis totais, medindo-se a absorbância em espectrofotômetro UV/VIS (Quimis modelo Q-108U) a $280 \mathrm{~nm}$; e os índices 420, 520 e 620, medindo-se a absorbância em espectrofotômetro a 420,520 e $620 \mathrm{~nm}$, respectivamente (CURVELO-GARCIA, 1988).

\subsection{Determinação de aminas bioativas}

Dez aminas bioativas foram pesquisadas, dentre elas, espermidina, espermina, putrescina, agmatina, cadaverina, serotonina, histamina, tiramina, triptamina e feniletilamina. Estas foram separadas por CLAE-par iônico em coluna de fase reversa, derivadas pós coluna com $o$-ftalaldeído e quantificadas por fluorimetria a $340 \mathrm{~nm}$ de excitação e $445 \mathrm{~nm}$ de emissão (SOUZA et al., 2005).

\section{Resultados e discussão}

\subsection{Características do mosto}

O deslocamento do ciclo da planta através da poda visando a produção durante o inverno permitiu maior avanço na maturação das bagas com reflexos positivos na composição físico-química dos vinhos. Neste caso, os cachos permaneceram nas plantas, em média, 24 dias adicionais (Tabela 2).

Considerando-se os aspectos qualitativos de composição em açúcares ( ${ }^{\circ}$ Brix) e acidez do mosto, a safra de 2006 produziu, nas colheitas de verão e inverno, bagas com maior teor de açúcares e menor acidez quando comparada à safra de 2005. Neste caso, não houve alteração no período de maturação das bagas, uma vez que o ciclo foi igual nos dois períodos avaliados, 159 e 183 dias após a poda (DAP) para as safras de verão e inverno de 2005, e 157 e 180 DAP no ano de 2006, respectivamente. Entretanto, a safra de 2006 foi caracterizada por um intenso veranico no período da maturação (Figura 1), marcado por um período de 19 dias sem precipitação pluviométrica. Tal condição permitiu maior avanço na maturação das bagas e a vinificação sem necessidade de chaptalização no inverno.

Jackson e Lombard (1993) observaram que o excesso de umidade pode retardar o amadurecimento, elevar o $\mathrm{pH}$ do mosto e o conteúdo em ácidos devido ao contínuo e excessivo crescimento dos ramos que aumentam o sombreamento. Além disso, a presença de nuvens pode limitar a exposição das plantas à luz de forma suficiente a reduzir a fotossíntese líquida e a composição das bagas em sólidos solúveis e ácidos. Um aumento da radiação, tanto em intensidade quanto em duração, pode ocasionar um aumento na produção e/ou teor de sólidos 
solúveis. Uma maior radiação aumenta a temperatura das folhas e bagas expostas, ocasionando um aumento na fotossíntese e atividade metabólica.

\subsection{Características físico-químicas do vinho}

Os resultados analíticos obtidos para o vinho estão indicados na Tabela 3. Os resultados da acidez titulável confirmam uma redução nos valores do vinho em relação ao mosto, com exceção do valor observado no verão de 2006 (Tabelas 2 e 3).

Os valores de acidez volátil observados estão elevados em relação aos obtidos nos vinhos das cultivares Merlot e Cabernet Franc elaborados na Serra Gaúcha, ao redor de 6,5 meq.L $\mathrm{L}^{-1}$ (RIZZON; MIELE, 2003; MANFROI et al., 2006), porém aproximam-se dos valores obtidos para as cultivares Cabernet Sauvignon e Tannat, cerca de 10 meq. L $^{-1}$ observados nas safras de 1987 a 1994 na Serra Gaúcha (RIZZON; MIELE, 2002; 2004).

Os valores de $\mathrm{pH}$ aumentaram durante a transformação do mosto em vinho, provavelmente devido a extração do potássio presente na casca no momento da maceração (Tabelas 2 e 3). Entretanto, o aumento do $\mathrm{pH}$ observado no vinho de inverno foi superior ao do vinho de verão $(3,91 \times 3,51$ na safra de 2005 e 3,77 $\times 3,58$ na safra de 2006, Tabela 3). A colheita no inverno levou a um aumento no $\mathrm{pH}$ dos vinhos acima da faixa considerada ideal para vinhos tintos $(3,1$ a 3,6$)$, o que deve ter contribuído para a maior acidez volátil destes vinhos. De acordo com Amerine e Ough (1980), valores elevados de $\mathrm{pH}$ expõem os vinhos a alterações microbiológicas e físico-químicas prejudiciais a sua estabilidade.

Os vinhos de inverno apresentaram maiores teores de extrato seco, extrato seco reduzido e cinzas (Tabela 3). A menor diferença observada entre as safras de verão e inverno no ano de $2006\left(0,1 ; 0,25\right.$ e 0,13 g. $L^{-1}$, respectivamente para os teores de extrato seco, extrato seco reduzido e cinzas) em relação à diferença observada entre as safras de verão e inverno no ano de 2005 (3,51; 3,35 e 0,83 g.L. $\left.{ }^{-1}\right)$ deve ser decorrente da melhor maturação das bagas na safra de verão de 2006, transcorrida sob condições de veranico intenso (Figura 1).

Os vinhos de verão apresentaram maior conteúdo de potássio. Este resultado era esperado, uma vez que a maturação das bagas durante o verão ocorre em condição de maior disponibilidade hídrica no solo. Entretanto, o teor de potássio no vinho, além de ser função da cultivar e das condições climáticas durante o desenvolvimento e época da colheita, é dependente das temperaturas de fermentação e de armazenamento, do tempo de armazenamento, do $\mathrm{pH}$, da porcentagem de álcool e do equilíbrio iônico do vinho (MANFROI et al., 2006).
Independente do tempo de armazenamento, os vinhos provenientes da colheita de inverno destacaram-se na composição em compostos fenólicos e intensidade de cor (Tabela 3). Diversos autores afirmaram que a temperatura é o principal fator que influencia na síntese e no acúmulo de antocianinas nas bagas, sendo que temperaturas elevadas promovem diminuição dos teores de antocianinas e elevada amplitude térmica promove maior acúmulo destes compostos (CHAMPAGNOL, 1984; JACKSON; LOMBARD, 1993; SPAYD et al., 2002; MORI; SUGAYA; GEMMA, 2004; DOWNEY; DOKOOZLIAN; KRSTIC, 2006).

$\mathrm{Na}$ elaboração do vinho tinto, as antocianinas e os taninos presentes na casca e nas sementes são transferidos ao vinho durante o processo de maceração. Na safra de verão, que apresentou temperaturas maiores e amplitude térmica menor, a concentração de antocianinas e fenólicos totais nos vinhos foi menor.

Tabela 3. Características físico-químicas do vinho Syrah proveniente de colheita de verão e inverno, nas safras de 2005 e 2006, no município de Três Corações (MG).

\begin{tabular}{|c|c|c|c|c|}
\hline \multirow{2}{*}{$\begin{array}{l}\text { Características } \\
\text { físico-químicas }\end{array}$} & \multicolumn{2}{|c|}{ Safra 2005} & \multicolumn{2}{|c|}{ Safra 2006} \\
\hline & Verão & Inverno & Verão & Inverno \\
\hline Densidade relativa $\left(20 / 20^{\circ} \mathrm{C}\right)$ & 0,9948 & 0,9936 & 0,9968 & 0,9938 \\
\hline Álcool (\% v/v) $20^{\circ} \mathrm{C}$ & 10,78 & 12,65 & 11,19 & 12,52 \\
\hline Acidez titulável (meq. $\mathrm{L}^{-1}$ ) & 86,70 & 88,00 & 103,02 & 75,00 \\
\hline Acidez volátil (meq.L -1) $^{-1}$ & 8,92 & 12,44 & 10,26 & 12,33 \\
\hline $\mathrm{pH}$ & 3,59 & 3,91 & 3,58 & 3,77 \\
\hline Açúcares redutores $\left(\mathrm{g} \cdot \mathrm{L}^{-1}\right)$ & 0,84 & 1,16 & 1,24 & 1,09 \\
\hline Extrato seco $\left(\mathrm{g} . \mathrm{L}^{-1}\right)$ & 16,82 & 20,33 & 21,05 & 21,15 \\
\hline Extrato seco reduzido (g.L $\left.\mathrm{L}^{-1}\right)$ & 16,82 & 20,17 & 20,81 & 21,06 \\
\hline $\begin{array}{l}\text { Álcool em peso/extrato seco } \\
\text { reduzido }\end{array}$ & 5,13 & 5,02 & 4,30 & 4,76 \\
\hline Cinzas $\left(\mathrm{g} . \mathrm{L}^{-1}\right)$ & 1,93 & 2,76 & 2,04 & 2,17 \\
\hline $\mathrm{K}\left(\mathrm{mg} \cdot \mathrm{L}^{-1}\right)$ & 960,75 & 914,05 & 975,63 & 838,35 \\
\hline $\begin{array}{l}\text { Dióxido de enxofre total } \\
\left(\mathrm{mg} \cdot \mathrm{L}^{-1}\right)\end{array}$ & 51,20 & 83,20 & 57,60 & 73,60 \\
\hline $\begin{array}{l}\text { Dióxido de enxofre livre } \\
\left(\mathrm{mg} \cdot \mathrm{L}^{-1}\right)\end{array}$ & 25,60 & 40,00 & 38,40 & 38,40 \\
\hline Antocianinas (mg. $\left.\mathrm{L}^{-1}\right)$ & 41,09 & 121,48 & 184,49 & 217,18 \\
\hline Fenólicos totais $\left(\mathrm{g} . \mathrm{L}^{-1}\right)$ & 1,21 & 2,06 & 1,48 & 2,15 \\
\hline Polifenóis totais (I 280) & 32,50 & 49,20 & 43,30 & 56,30 \\
\hline Índice 420 & 2,36 & 4,13 & 3,71 & 5,00 \\
\hline Índice 520 & 2,74 & 5,13 & 6,15 & 7,46 \\
\hline Índice 620 & 0,58 & 1,48 & 1,19 & 1,87 \\
\hline Intensidade $\left(\mathrm{I}_{420}+\mathrm{I}_{520}+\mathrm{I}_{620}\right)$ & 5,68 & 10,74 & 11,05 & 14,33 \\
\hline Coloração $\left(\mathrm{I}_{420} / \mathrm{I}_{520}\right)$ & 0,86 & 0,81 & 0,60 & 0,67 \\
\hline Aminas bioativas $\left(\mathrm{mg} . \mathrm{L}^{-1}\right)$ & 4,46 & 10,36 & 2,22 & 4,19 \\
\hline
\end{tabular}

Tabela 2. Teores de sólidos solúveis totais (SST), acidez titulável e pH no mosto das bagas da videira Syrah em ciclos de verão e inverno nas safras de 2005 e 2006 no município de Três Corações (MG).

\begin{tabular}{|c|c|c|c|c|}
\hline \multirow[t]{2}{*}{ Composição do mosto } & \multicolumn{2}{|c|}{ Safra 2005} & \multicolumn{2}{|c|}{ Safra 2006} \\
\hline & Verão & Inverno & Verão & Inverno \\
\hline SST $\left({ }^{\circ}\right.$ Brix $)$ & $15,86 \pm 0,34^{\mathrm{b}}$ & $18,24 \pm 0,17^{a}$ & $17,38 \pm 0,27^{\mathrm{B}}$ & $20,66 \pm 0,46^{\mathrm{A}}$ \\
\hline Acidez titulável (meq. $\mathrm{L}^{-1}$ ) & $121,20 \pm 4,60^{\mathrm{a}}$ & $108,12 \pm 3,23^{b}$ & $102,60 \pm 0,89^{\mathrm{B}}$ & $105,15 \pm 1,90^{\mathrm{A}}$ \\
\hline $\mathrm{pH}$ & $3,46 \pm 0,10^{\mathrm{a}}$ & $3,44 \pm 0,04^{\mathrm{a}}$ & $3,39 \pm 0,04^{\mathrm{A}}$ & $3,26 \pm 0,02^{\mathrm{B}}$ \\
\hline
\end{tabular}

Médias seguidas de mesma letra minúscula nas colunas verão e inverno 2005 e maiúsculas nas colunas verão e inverno 2006 não diferem entre si significativamente pelo teste de Tukey $(\mathrm{p} \leq 0,05)$. 
A coloração do vinho da safra de 2005 foi maior do que a da safra de 2006 (Tabela 3). De acordo com Manfroi et al. (2006), a relação 420/520 aumenta com o envelhecimento devido à combinação entre os taninos e as antocianinas presentes no vinho. A redução no teor de antocianinas devido ao envelhecimento do vinho provavelmente deve ter contribuído para os menores valores de antocianinas, polifenóis totais e intensidade de cor observados nos vinhos de verão e inverno da safra de 2005, uma vez que a análise foi realizada nos vinhos armazenados por mais tempo (13 meses para a safra de 2005, contra apenas 2 meses para a safra de 2006).

\subsection{Tipo e teores de aminas bioativas no vinho}

Os teores totais de aminas bioativas encontrados nos vinhos estão indicados na Tabela 3. Maiores teores de aminas foram encontrados no inverno, independente da safra. Entretanto, no inverno de 2005, os teores foram significativamente maiores que no inverno de 2006. Diferentemente da composição do vinho, o tempo de armazenamento não afeta de modo significativo os teores de aminas, uma vez que não há crescimento microbiano e a ação das enzimas descarboxilantes pode ser inibida pelas condições de $\mathrm{pH}$.

Dentre as dez aminas pesquisadas, nove foram detectadas nas amostras de vinhos analisadas (Tabela 4). Apenas a triptamina não foi encontrada. A presença destas aminas em vinhos já havia sido descrita na literatura (GLÓRIA et al., 1998; SOUZA et al., 2005; MO DUGO et al., 2006; GLÓRIA; VIEIRA, 2007; MILLÁN et al., 2007; SOUFLEROS et al., 2007; YILDIRIM; ÜREN; YÜCEL, 2007). As poliaminas espermidina e espermina estão associadas à morfogênese da planta, atuando como reguladores do crescimento e como resposta aos desafios ambientais. Agmatina e putrescina são precursoras das poliaminas via arginina e ornitina, respectivamente. Serotonina, histamina e as aminas aromáticas podem estar associadas com os mecanismos de defesa da planta protegendo-as contra predadores (COUTTS; BAKER; PASUTTO, 1986; KUZNETSOV; SHEVYAKOVA, 2007; PANG et al., 2007). Ainda, a microbiota da uva associada às condições edafoclimáticas durante a produção, podem afetar de forma significativa o perfil das aminas, pela descarboxilação de aminoácidos do mosto pelas enzimas bacterianas (KISS; KORBÁZ; SASS-KISS, 2006).

Tabela 4. Tipos e teores de aminas bioativas $\left(\mathrm{mg} . \mathrm{L}^{-1}\right)$ em vinhos Syrah provenientes de colheita de verão e inverno, das safras de 2005 e 2006, no município de Três Corações (MG).

\begin{tabular}{lcccc}
\hline $\begin{array}{c}\text { Aminas } \\
\text { bioativas }\end{array}$ & $\begin{array}{c}\text { Verão 2005 } \\
\left(\mathrm{mg} . \mathrm{L}^{-1}\right)\end{array}$ & $\begin{array}{c}\text { Inverno 2005 } \\
\left(\mathrm{mg} \cdot \mathrm{L}^{-1}\right)\end{array}$ & $\begin{array}{c}\text { Verão 2006 } \\
\left(\mathrm{mg} . \mathrm{L}^{-1}\right)\end{array}$ & $\begin{array}{c}\text { Inverno 2006 } \\
\left(\mathrm{mg} . \mathrm{L}^{-1}\right)\end{array}$ \\
\hline Triptamina & nd & nd & nd & nd \\
Feniletilamina & nd & nd & nd & 0,11 \\
Espermina & 0,20 & nd & 0,27 & 0,25 \\
Espermidina & 0,08 & 0,89 & 0,21 & 0,37 \\
Agmatina & 0,07 & 0,06 & 0,09 & 0,08 \\
Serotonina & 0,03 & 0,17 & nd & nd \\
Tiramina & 1,33 & nd & nd & nd \\
Histamina & 0,16 & 6,46 & 0,09 & 0,07 \\
Cadaverina & 1,55 & nd & nd & nd \\
Putrescina & 0,93 & 2,78 & 1,56 & 3,32 \\
\hline
\end{tabular}

nd $=$ não detectado, $\leq 0,04 \mathrm{mg} \cdot \mathrm{L}^{-1}$.
Na safra de 2006, foi observada uma menor diversidade de aminas comparada a de 2005 (Tabela 4). Apesar dos teores e tipos de aminas em vinhos serem afetados pelas condições higiênico-sanitárias durante a produção do vinho, esta variável não seria relevante neste estudo uma vez que os vinhos foram produzidos em condições padronizadas em ambas as safras. Assim sendo, as diferenças no perfil de aminas entre as safras são devidas às condições edafoclimáticas, que podem afetar os teores de aminoácidos livres e a microbiota da uva (HERBERT et al., 2006; KISS, KORBÁZ; SASS-KISS, 2006; MARTÍN-ÁLVAREZ et al., 2006). A menor diversidade de aminas em 2006, associadas a um menor teor total de aminas, sugerem que as condições prevalentes neste ano favoreceram a qualidade do vinho quanto às aminas bioativas.

Na safra de 2005, houve uma maior diversidade e maiores teores de aminas (Tabela 4). No verão de 2005, cadaverina, putrescina e tiramina foram as aminas predominantes, contribuindo com $87,6 \%$ do teor total das aminas do vinho $(1,55,0,93$, e $1,33 \mathrm{mg} . \mathrm{L}^{-1}$, respectivamente). Esta safra foi caracterizada por alta precipitação na época da colheita e elevado $\mathrm{pH}$ das uvas, o que pode ter favorecido o crescimento de uma microbiota mais complexa com consequente produção destas aminas (MARTÍN-ÁLVAREZ et al., 2006). Já no inverno de 2005, histamina foi a amina predominante, representando $62,4 \%$ do teor total de aminas, sugerindo uma síntese aumentada de histidina ou a predominância de microbiota da uva com potencial histidina descarboxilase.

Os maiores teores de putrescina foram observados no inverno nas duas safras (Tabela 4). A estação seca durante o cultivo das uvas pode ter ocasionado um estresse hídrico, ou pode ter ocorrido uma deficiência de potássio e, consequentemente, um acúmulo de putrescina na uva (WALTERS, 2003; GLÓRIA; VIEIRA, 2007).

Embora a legislação brasileira ainda não estabeleça um limite para a concentração de aminas nos vinhos, países como a Suíça recomendam um nível máximo de $10 \mathrm{mg} \cdot \mathrm{L}^{-1}$ de histamina; a Alemanha, $2 \mathrm{mg} . \mathrm{L}^{-1}$; a Bélgica, $5 \mathrm{mg} . \mathrm{L}^{-1}$; e a França, $8 \mathrm{mg} . \mathrm{L}^{-1}$ (LEHTONEN, 1996). Os valores de histamina observados nos vinhos de Três Corações, exceto o do inverno de 2005, encontram-se dentro dos limites recomendados pelos países europeus.

\section{Conclusões}

Vinhos elaborados a partir de uvas colhidas no inverno, sob condições de menor índice pluviométrico e maior amplitude térmica, apresentaram maior conteúdo de compostos fenólicos e índice de cor, além de não haver necessidade de chaptalização. Estas condições conferem maior qualidade ao vinho e maior potencial de guarda. Entretanto, o elevado $\mathrm{pH}$ do mosto aumenta a instabilidade do vinho e contribui para um aumento no teor de aminas bioativas, cuja evolução deve ser controlada no processo de vinificação.

\section{Agradecimentos}

Os autores agradecem à FAPEMIG e ao CNPq o apoio financeiro e à Fazenda da Fé a cessão da área experimental do vinhedo. 


\section{Referências bibliográficas}

AMERINE, M. A.; OUGH, C. S. Methods for analysis of musts and wines. New York: John Wiley \& Sons, 1980. 341 p.

AMORIM, D. A.; FAVERO, A. C.; REGINA, M. A. Produção extemporânea da videira, cultivar Syrah, nas condições do sul de Minas Gerais. Revista Brasileira de Fruticultura, v. 27, n. 2, p. 327-331, 2005.

ASSOCIATION OF OFFICIAL ANALYTICAL CHEMISTS - AOAC. Official methods of analysis. Washington, 1995.

CHAMPAGNOL, F. Elements de Physiologie de la Vigne et de Viticulture Generale. Saint-Gely-du-Fesc: Champagnol, 1984. 351 p.

COUTTS, R. T.; BAKER, G. B.; PASUTTO, F. M. Foodstuffs as sources of psychoactive amines and their precursors: content, significance and identification. Advances in Drug Research, v. 15, n. 1, p. 169-232, 1986.

CURVELO-GARCIA, A. S. Polifenóis. A cor dos vinhos. In: Controlo de qualidade dos vinhos. Lisboa: Instituto da Vinha e do Vinho, 1988. p. 311-347.

DOWNEY, M. O.; DOKOOZLIAN, N. K.; KRSTIC, M. P. Cultural practice and environmental impacts on the flavonoid composition of grapes and wine: a review of recent research. American Journal of Enology and Viticulture, v. 53, n. 3, p. 257-268, 2006.

FAVERO, A. C. Viabilidade de produção da videira Syrah, em ciclos de verão e inverno no sul de Minas Gerais. 2007. 114 p. Dissertação (Mestrado em Fitotecnia) - Universidade Federal de Lavras, Lavras, 2007.

GIUSTI, M. M.; WROSLTAD, R. E. Characterization and measurement of anthocyanins by uv-visible spectroscopy. In: WROLSTAD, R. E. Current Protocols in Food Analytical Chemistry. New York: John Willey \& Sons, 2000.

GLÓRIA, M. B. A.; VIEIRA, S. M. Technological and toxicological significance of bioactive amines in grapes and wines. Food, v. 1, n. 2, p. 258-270, 2007.

GLÓRIA, M. B. A. et al. A survey of biogenic amines in Oregon Pinot noir and Cabernet Sauvignon wines. American Journal of Enology and Viticulture, v. 49, n. 3, p. 279-282, 1998.

GUERRA, C. C. Maturação da uva e condução da vinificação para a elaboração de vinhos finos. In: REGINA, M. A. (Coord.). Viticultura e Enologia: Atualizando Conceitos. Caldas: EPAMIG; FECD, 2002. p. 179-192.

HERBERT, P. et al. Relationship between biogenic amines and free amino acid contents of wines and musts from Alentejo (Portugal). Journal of Environmental Science and Health - Part B Pesticides, Food Contaminants, and Agricultural Wastes, v. 41, n. 7, p. 1171-1186, 2006.

JACKSON, D. I.; LOMBARD, P. B. Environmental and management practices affecting grape composition and wine quality - a review. American Journal of Enology and Viticulture, v. 44, n. 4, p. 409-430, 1993.

KISS, J.; KORBÁZ, M.; SASS-KISS, A. Study of amine composition of botrytized grape berries. Journal of Agricultural and Food Chemistry, v. 54, n. 23, p. 8909-8918, 2006.

KUZNETSOV, V. V.; SHEVYAKOVA, N. I. Polyamines and stress tolerance of plants. Plant Stress, v. 1, n. 1, p. 50-71, 2007.

LEHTONEN, P. Determination of amines and amino acids in wine: a review. American Journal of Enology and Viticulture, v. 47, n. 2, p. 127-133, 1996.

MANFROI, L. et al. Composição físico-química do vinho Cabernet Franc proveniente de videiras conduzidas no sistema lira aberta. Ciência e Tecnologia de Alimentos, v. 26, n. 2, p. 290-296, 2006.
MARTÍN-ÁLVAREZ, P. J. et al. Influence of technological practices on biogenic amine contents in red wines. European Food Research and Technology, v. 222, n. 3-4, p. 420-424, 2006.

MILLÁN, S. et al. Simple and rapid determination of biogenic amines in wine by liquid chromatography-electrospray ionization ion trap mass spectrometry. Analytica Chimica Acta, v. 584, n. 1, p. 145-152, 2007.

MO DUGO, G. et al. Reverse phase HPLC/DAD determination of biogenic amines as dansyl derivatives in experimental red wines. Food Chemistry, v. 95, n. 4, p. 672-676, 2006.

MORI, K.; SUGAYA, S.; GEMMA, H. Regulatory mechanism of anthocyanin biosynthesis in 'Kyoto' grape berries grown under different temperatures conditions. Environmental Control in Biology, v. 42, n. 1, p. 21-30, 2004.

PANG, X. M. et al. Polyamines, all-purpose players in response to environment stresses in plants. Plant Stress, v. 1, n. 2, p. 173-188, 2007.

REGINA, M. A. et al. Novos pólos vitícolas para produção de vinhos finos em Minas Gerais. Informe Agropecuário, v. 27, n. 234, p. 111-118, 2006.

RIBÉREAU-GAYON, P. et al. Le Raisin et sa maturation. In: Traité d’oenologie: 1. Microbiologie du vin. Vinifications. Paris: Dunod, 2004. p. 315-395.

RIZZON, L. A.; MIELE, A. Avaliação da cv. Cabernet Sauvignon para elaboração de vinho tinto. Ciência e Tecnologia de Alimentos, v. 22, n. 2, p. 192-198, 2002.

RIZZON, L. A.; MIELE, A. Avaliação da cv. Merlot para elaboração de vinho tinto. Ciência e Tecnologia de Alimentos v. 23 (supl.), p. 151-161, 2003.

RIZZON, L. A.; MIELE, A. Avaliação da cv. Tannat para elaboração de vinho tinto. Ciência e Tecnologia de Alimentos v. 24, n. 2, p. 223-229, 2004.

SOUFLEROS, E. et al. Determination of biogenic amines in Greek wines by HPLC and ultraviolet detection after dansylation and examination of factors affecting their presence and concentration. Food Chemistry, v. 101, n. 2, p. 704-716, 2007.

SOUZA, S. C. et al. Bioactive amines in Brazilian wines: types, levels and correlation with physico-chemical parameters. Brazilian Archives of Biology and Technology, v. 48, n. 1, p. 53-62, 2005.

SPAYD, S. E. et al. Separation of sunlight and temperature effects on the composition of Vitis vinifera cv. Merlot Berries. American Journal of Enology and Viticulture,v. 53, n. 3, p. 171-182, 2002.

TONIETTO, J.; VIANELLO, R. L.; REGINA, M. A. Caracterização macroclimática e potencial enológico de diferentes regiões com vocação vitícola em Minas Gerais. Informe Agropecuário, v. 27, n. 234, p. 32-55, 2006.

UBALDE, J. M. et al. Influence of edapho-climatic factors on grape quality in Conca de Barberà Vineyards (Catalonia, Spain). Journal International des Sciences de la Vigne et du Vin, v. 41, n. 1, p. 33-41, 2007.

Van LEEUWEN, C. et al. Influence of climate, soil and cultivar on terroir. American Journal of Enology and Viticulture, v. 55, n. 3, p. 207-217, 2004.

WALTERS, D. R. Polyamines and plant disease. Phytochemistry, v. 64, n. 1, p. 97-107, 2003.

YILDIRIM, H. K.; ÜREN, A.; YÜCEL, U. Evaluation of biogenic amines in organic and non-organic wines by HPLC OPA derivatization. Food Technology and Biotechnology, v. 45, n. 1, p. 62-68, 2007. 